\title{
IMAGINING TRANSPECIES KINSHIP IN XENOTRANSPLANTATION
}

\author{
Lesley A. Sharp
}

\begin{abstract}
Xenotransplantation, as a highly experimental realm of science, is plagued by serious moral concerns: driven in part by the imperative to alleviate human suffering in a medical realm plagued by a scarcity in human organs, xeno experts must nevertheless quell public concern over the use of animals as 'donor'species, and the potential threats xenografting poses to human body integrity. Embedded within the language of xeno science is an intriguing grammar of kinship, one which reorders unsettling ideas of 'monstrous' science as a legitimate field intent on establishing interspecies compatibility. As this article illustrates, a logic of kinship abounds within the realm of organ transfer more generally, yet it takes on special meanings within the rarified world of experimental xenotransplantation, where a range of bodies-be they animal or human-occupy highly vulnerable positions in the scientific search for transpecies integrity.
\end{abstract}

\section{INTRODUCTION}

Within the United States, where I live and work, a widespread understanding (and unchallenged social fact) is that organ transplantation is in crisis, plagued by severe shortages in organs of human origin. Although surgically successful allografts date back to the 1950s, effective immunosuppression three decades later accounts in large part for this national predicament: as virtually all professional essays, books, conference proceedings, and mass media accounts proclaim, the number of patients awaiting organs far surpasses the supply of donated body parts, and the gap only continues to grow, generating widespread anxiety in the States and, now, increasingly abroad. Transplant medicine is in desperate need of creative solutions, and these range from the call in various quarters to alter procurement protocols, commercialize transactions with living donors or the surviving kin of deceased ones, and generate alternative 
sources for transplantable parts.

Alternative - albeit still highly experimental - research includes tissue engineering, or growing new organs ex vivo from seeded cell cultures; efforts among bioengineers to design 'artificial' or mechanical parts; and xenotransplantation (henceforth xeno), or the use of animals - especially primates and, more recently pigs - whose organs might one day be implanted in humans, a field where New Zealand may well take the lead someday soon (Garkavenko et al., 2005, Mandell, 2010). Each alternative bears the promise of alleviating human suffering by eliminating transplant medicine's dependence on a finite number of altruistic human donors. This looming moral imperative both justifies and drives the work of those engaged in experimental research.

Each of these potential solutions is troubled by serious obstacles: although attempts have successfully generated tubular tissues (including the trachea, vagina, and uterus), significant hurdles undermine efforts to grow organs as complex as the kidney, heart, or liver; mechanical parts can only approximate the workings of major organs; and xeno experts struggle to 'match' organs from disparate species without generating life-threatening immunological responses. Xeno efforts are further complicated by activists who oppose the medical use of or genetic tampering with species, protests which rest alongside a more widespread public aversion for creating potentially monstrous entities by implanting animals' fleshy parts in humans. The social complexities of these challenges intrigue me as a medical anthropologist.

An approach that guides many anthropologists is that we 'render the strange familiar and the familiar strange,' (Geertz [1973:215] after Percy [1958], Malinowski, 1961 [1922]), one that facilitates the process of deciphering behaviors and embedded symbolic meanings within specific cultural contexts. That is, we pay special attention to formal and informal rules, patterned behaviors, turns of phrase, categories of representation, and ideas of social relatedness, such as kinship. In this light, it requires little imagination to see allo- and xeno-grafting as altogether 'strange' practices because such attempts challenge species integrity. As I shall illustrate below, xeno's very strangeness proves to be of significant interest and value not simply for the wider public, but among experts, too.

Now nearly routine in clinical quarters, human organ transfer ${ }^{1}$ is considered by the well-informed to be socially unproblematic; when viewed from a lay point of view, however, there is something altogether strange about the medical use of allografts, precisely because their surgeries require the full excision of a recipient's ailing 'natal' organ and its replacement through the transfer 
and implantation of fleshy parts derived from another living or dead 'donor.' When viewed as such, organ transfer involves the radical breaching of corporeal boundaries and the quite literal suturing together of two bodies into one. Furthermore, in the drive to alleviate human suffering, some argue that potentially any freshly dead body could provide a few to over a hundred reusable parts; and some parties even regard kidneys, lungs, liver lobes, and corneas as redundant organs that can (or should) be acquired from healthy, living people to assist those in need.

An ongoing challenge that arises with each new donation, sickly patient, or policy revision is how to naturalize the strangeness of these body transfers. In the U.S., involved parties generate intriguing responses to allografts: most notably, various idioms of relatedness - or kinship - override anxieties of organ transfer's strange or 'monstrous' qualities, and efforts to reconfigure these transfers through the idiom of kinship emerge with surprising frequency. Even more intriguing is the manner in which the logic of kinship figures within xeno experts' understandings of their experimental activities, too. Also, this logic is expressed by scientists based in various Anglophone countries (U.S., Canada, U.K., Australia, and New Zealand); as such, together they comprise a small, specialized, and interconnected community with shared values about experimental xeno research.

Within this essay I probe the meanings associated with intra- and inter-species relatedness; as I will show, kinship idioms naturalize the melding of disparate bodies in both quotidian and experimental transplant settings. To contextualize my arguments, I offer a brief overview of how anthropologists think about kinship as they map and decipher social worlds, and how kinship figures in American responses to intraspecies allografts. I regard xeno as an experimental branch of the much larger field of human organ transfer, and I thus examine how xeno experts' understandings of interspecies kinship surface, order, and legitimate the highly experimental use of non-human primates and, more recently, of pigs as appropriate 'donor' species (as involved scientists describe them). The stakes in xeno are high because experimental work is morally tentative on multiple fronts. More specifically, xeno is driven by forces that are simultaneously economic (if successful, it could alleviate organ scarcity or even render allotransplants obsolete); immunological (it must overcome the life threatening consequences of interspecies graft incompatibility); and social because it requires public acceptance of particular species as appropriate donor matches. As I shall show, in the desire to accomplish inter-species melding, the idiom of kinship may either legitimate or condemn the preferential use of particular animals. 
The material reported here is drawn from two interrelated projects: the first consists of nearly two decades of ethnographic fieldwork on organ transfer in the U.S., with special attention given to the socio-moral consequences of allotransplants. In 2004, my work shifted to xeno and other experimental efforts in five Anglophone countries. ${ }^{2}$ This most recent project is framed by what I will reference as the scientific imagination (DelVecchio Good, 2001): that is, how do involved scientists think about the purpose and consequences of experimental research as anticipatory science (Sharp, 2011), and how do they express its moral parameters in their actions and words. My ethnographic work is driven by several anthropological assumptions: most notably, that human life is characterized by contradictions and, thus, moments of conflict and associated anxieties enable us to decipher moral parameters or ethos of particular societies (Bateson, 1958, Brodwin, 2000, Fisher, 2002). In addition, categories of sociality or relatedness figure prominently as a means to order human life, where kinship is understood as an especially potent idiom for expressing and, even, legitimating social proximity.

Within my own sub-field of training of medical anthropology, we have long regarded biomedicine as a specialized cultural system (DelVecchio Good, 1995), and the same may be said of tran splantation. Promotional efforts underscore for clinicians, patients, and the wider public that human organ transfer is a logical, routine, and humanitarian practice, with media campaigns designed specifically to squelch fears that this is 'strange,' 'mad' or 'monstrous' medicine. As I describe elsewhere (Sharp, 2001, Sharp, 2006), key messages emphasize that transplants are miraculous 'gifts of life'; organ donation is a moral imperative and a great social good; yet organs retain none of their donors' qualities but are simply replaceable 'pumps' and 'filters.' Professionals squelch discussions of donors as living on in patients, talk that they consider naïve, misinformed, and pathological. An older literature maintains that patients who believe they have been pieced together with parts from disparate bodies might be diagnosed with 'Frankenstein Syndrome' and referred for psychiatric counseling.

A tension inherent in this biomedical realm is how to make proper rather than illegitimate use of organs derived from the dead. Involved parties must subdue anxieties over the potentially 'monstrous' aspects of body transfers. Whereas professionals do so by rendering organs inert, others defy through idioms of kinship. For instance, transplant recipients and deceased donors' relatives render the strange familiar by turning anonymous strangers into kin. Many recipients search for their 'donor families' (and note, not their donors' families), where successful encounters may foster long-lasting, sentimental bonds among newfound blood kin, sometimes spanning racial, ethnic, or national divides. 
Among the most significant is that between a recipient and his or her 'donor mother', a woman who birthed the deceased donor and subsequently enabled the recipient's 'rebirth' through organ donation (Sharp, 2006:203ff).

Although xeno research remains highly experimental and so far no patients have survived such radical surgeries long enough to confront the complexities of embodying interspecies hybridity, xeno research similarly struggles to tame or naturalize its own set of monsters through the idiom of kinship. With this in mind, I will consider the following questions. Of what relevance is kinship to xeno research, and why should sociality even matter? What do categories of sameness and difference reveal about the legitimacy of scientific claims where interspecies hybridity is concerned? How do these categories figure within - and shape - the scientific imagination? What do they say about the moral parameters of embodied hybridity in experimental science? To answer these questions, we must first consider the strategic qualities of kinship classifications.

\section{KINSHIP MATTERS}

Relatedness, sameness, kinship, and kind - as anthropologists know, the potency of such categories lies in their power to render strange things familiar by transforming foreigners and foes into kith and kin. The study of kinship has long figured within anthropological methodology and analysis, defining one of the oldest grammars for deciphering the logic of particular socio-moral worlds. A foundational work from 1910, authored by W.H.R. Rivers - who was both physician and anthropologist - detailed the 'genealogical method,' an approach that rapidly became a standard methodology for tracing human relations and associated values across generations (Rivers, 1971). Rivers outlined the rigor necessary for mapping relationships (or what he called 'pedigrees') within small-scale societies. Subsequently, anthropologists have long considered kinship a deeply entrenched logic that drives and sustains sociality over time. Never static, kinship is indeed best understood as a temporal, dynamic, and thus transformative process that orders (or reorders) social worlds and impinges, in turn, on configurations of selfhood or subjectivity. When anthropologists approach kinship as a social process, they encounter a lively dialectic, where categories of relatedness interact with a highly localized ethos. For instance, marriage may transform outsiders into insiders; lines of descent may convert enemies into allies; and shared origins can foster cooperation over competition. Kinship thus transforms the 'strange' into 'same' when categories of relatedness are activated within highly specific socio-moral worlds. 
Three basic - yet key - analytical categories employed by anthropologists for classifying how people think about kin are especially helpful. First are those defined through shared blood or substance (relations determined by birth and descent); and those we refer to as affinal associations (or those generated through marriage). As anthropologists have long documented, blood and affinal ties are not understood universally across cultures: for instance, some view children as blood kin to both parents, whereas others recognize ties to only one. Some, too, insist on marrying within a designated group, whereas others marry out. In short, one must decipher local knowledge and practices when documenting configurations of kinship. In this light, categories of blood and affinal relatedness assist us in delineating sociality's moral parameters, where - if we generalize - blood relations ultimately mark sameness, whereas affines stand as desired (and, one hopes, sanctioned) categories of difference. Within this paired set of relations, incest emerges as an important third, albeit perverse category of sociality, because it is a tabooed inversion of sameness and strangeness.

Rivers espoused meticulous, rigid mapping as a means to generate a reliably stable template that would persist across generations in small-scale communities. Seventy years later, kinship has been reinvigorated by anthropologists interested in artificial reproductive technologies and genomics, generating work on how families are reconceived when, for instance, donor sperm, ova, and gestational surrogates figure in the mix (Strathern, 1992, Ragoné, 1996, Ginsburg and Rapp, 1995). Such developments generate conundrums about identity and origins, sometimes reducing relatedness to the molecular or genetic level and generating what Paul Rabinow has identified as new forms of 'biosociality' (Rabinow, 1992, building on Schneider, 1980 [1965]). As Rayna Rapp has shown, for instance, individuals who share genetic mutations and associated pathologies may now view each other as newfound kin (Rapp, 2000). Still others have tracked human relations with animals as companion species, preferred experimental subjects, and icons of national identity (with sheep in the U.K., primates in the U.S., and a transgenic bull in the Netherlands) (Franklin, 2007, Haraway, 1989, Taussig, 2004). How within science, then, might kinship categories distinguish insiders from outsiders, and what are the sociomoral consequences of such distinctions? Kinship, after all, is not simply about substance - it is also about sentiment and intimacy.

I propose returning to these older, established technical categories of belonging because I believe they offer productive, overarching idioms for deciphering scientific thinking. My analysis is also enabled by the very metaphors employed by involved scientists who are preoccupied with 'natal' bodies and their parts, 
tissue 'matching,' species 'compatibility', and the desire to transform difference into 'sameness' and 'self.' These are indeed intriguing metaphors that enable us to explore an internal logic that legitimates interspeciality.

Thus, the beauty of kinship analysis lies in its elasticity: its grammar is subjective and context specific; its associated meanings and categories polyvalent; it responds remarkably to temporal shifts; and its relevance and authenticity are dependent on moral parameters of interaction that ultimately define the outer limits of human sociality. These trends are evident within the moral world that defines organ transfer in the U.S., where a grammar of sameness confirms the legitimacy of associated medical practices. This grammar, however, is by no means standardized across domains but, rather, assumes a variance of forms. Transplant professionals, organ recipients, and the surviving kin of deceased donors each generate specialized notions of sociality that then resurface within the logic of xeno research.

THE MORALITY OF KINSHIP IN ORGAN TRANSFER

Within American transplant medicine, a range of parties relies on genealogical thinking to foreground social relatedness, reorder moral thinking, and legitimate clinical practices. Briefly, transplant surgeons evoke notions of sameness through the idiom of embodied 'compatibility', a term that evokes a marriage or sorts between disparate bodies. To draw on professionals' own language, organs must be a 'good match', measured in terms of 'size' and 'fit'; blood types must 'match,' too, to avoid life-threatening 'rejection'; further, patient survival depends on the daily ingestion of immunosuppressants that 'fool' the body into responding to the implanted organ as 'same' or 'self' rather than 'foreign.'

Yet rarely do recipients understand their organs in these terms, or as mechanistic parts, but as living flesh that harbors the essence, spirit, or soul of deceased donors. Whereas surgeons remake their bodies by suturing new tissue in place, recipients speak of their surgeries as enabling a 'rebirth' that occurs when donated organs, as 'gifts of life,' are transferred to and implanted within them. Many recipients speak of their anonymous donors as embodied intimates or guardian angels; furthermore, the language of kinship facilitates the reimagining of organ transfer as an unusual form of social intimacy. For instance, organ recipients may embrace their donors' surviving kin as newfound parents and siblings (and even address them as such). Donor kin likewise seek out those whose bodies harbor parts of their lost loved ones, and they may well incorporate these recipients as members of their respective kindred, including them as members of their most intimate circle of relations. Together then, organ 
recipients and donor kin transform organ transfer's strangeness into sameness and strangers into kin.

\section{ANIMA(TING) TRANSPECIES KINSHIP IN XENO RESEARCH}

Related ideas surface in xeno experts' understandings of the immunological and social potential of various animal species. An uncanny resemblance surfaces in reference to the ways that many Americans talk about blood kin versus affines and how involved xeno scientists in the U.S. and elsewhere imagine the promises of primates versus pigs over time. In essence, social readings of sameness and difference elide with scientific categories of compatibility. Furthermore, incompatibility might even be read as the looming threat of perverse or incestuous unions. In other words, the grammar of kinship is not merely relevant to seemingly archaic investigations of small-scale societies, but to presumed impersonal contexts of technocratic medicine and experimental science.

Categories of sameness and difference thus encourage us to consider legitimate and illegitimate forms of sociality. Furthermore - as I will illustrate below this is not simply about animals, but racial categories, too. If, for instance, xeno experts wish to meld animal parts with human bodies, publicly and professionally they must frame highly experimental efforts in socio-moral terms. A constant threat to xeno scientists is that their activities are perceived by others (as phrased by animal activists) as 'monstrous' forms of 'mad science.' In response, effective xeno research requires exiling the perverse monster by taming interspecies sociality, and xeno experts do this regularly by describing certain animals as our 'close cousins', ideal 'matches', and 'compatible' species.

\section{NATURALIZING THE MONSTER}

Anxieties about transplant's monstrous qualities expose the underbelly of these remarkable forms of imagined sociality. Transplant professionals, for example, bristle over the animate qualities assigned to organs by recipients and donor kin. But whereas they seemingly abhor Frankenstein's monster, they, alongside xeno experts, celebrate monstrousness in the form of the chimera. The original, mythological Chimera was a ravenous, fire-breathing, three-headed beast that terrorized villagers of ancient Greece. Within immunology, however, chimeras are creatures that unproblematically harbor genetic material from disparate bodies or species. Transplant patients - who take potent immunosuppressants - are sometimes described as pseudo-chimeras; and some physicians strive to wean patients off their drugs (transforming them into true chimeras). 
Celebrations of chimeras are indeed widespread within the medical realm of organ transplantation: for example, Chimera is the official newsletter of the American Society of Transplant Surgeons, which also has an associated 'Chimeric Chronicles' webpage. ${ }^{3}$ In essence, transplant medicine abhors monsters in socialized contexts, yet celebrates their naturalized form when reformulated within strictly immunological terms.

Nowhere is this celebration of monsters as pronounced as it is in xeno research, where often the most troubling (and socially disturbing) qualities of organ transfer are reconfigured as desired forms of compatibility. Driven by the moral imperative to alleviate human suffering, xeno experts deliberately manipulate immunological (in)compatibility, imagining new categories of transpecies kinship at the molecular level. 'Monsters' - conceived of as radical forms of interspecies pairings - emerge in newly tamed, scientific forms, thus heralding the radical transformation of strangeness or difference into sameness and self.

As an experimental science, however, xeno threatens to generate a host of uncanny and, thus, potentially disturbing socio-moral consequences, even though only certain kinds of animals define its prized 'donor' species. Xeno's success thus depends on widespread public acceptance that particular species make for appropriate human matches. Because of this, the field is in a radical state of flux, and over time it has shifted its investment in time, capital, and intellectual energy between non-human primate and porcine species, arguing that each, in turn, defines our closest 'cousins' or most 'compatible' 'matches' for radical forms of body melding. Furthermore - as I shall demonstrate below - only certain kinds of human bodies seem to qualify for such radical pairings.

How, then, are we to unpack ideas of interspecies sameness, closeness, kinship, and kind? Answers to this lie in the history of xeno itself, where several important temporal shifts flag emergent ideas about closeness and human/ animal compatibility.

\section{LEGITIMATE HISTORIES OF INTERSPECIES HYBRIDITY}

Although xenografting has yet to prove successful, the science itself is hardly new, with surgical efforts spanning more than a century. Involved experts have long hoped to isolate or breed specialized animals for their organs, and thus we must approach the field historically to track how they think about the legitimacy of their work and the appropriate pairing of certain animals with humans. Simians and swine are imagined differently, where notions of inter- 
species compatibility and kinship shift each from being altogether strange or perverse mates to fully and naturally embodied human companions.

Interestingly, within conference settings, publications, and professional discussions, xeno experts' presentations often feature a wide range of monsters culled from disparate cultures, comprised of descriptions and images of beasts culled from a range of cultures. These examples are pieced together as evidence of a historicized canon that foregrounds scientific ingenuity, inspired, radical thinking, and the natural propensity of our species to meld disparate bodies. Running contrary to critics' accusations, within professionalized contexts xeno research is not perverted mad science run amok, but instead offers one of myriad examples of a naturalized human desire to successfully combine materials derived from disparate species within a single body. The following overview, drawn from the opening of 'The History of Xenotransplantation' by Deschamps et al. (2005:91), is exemplary in this regard:

...The history of xenotransplantation shows that crossing the species barrier has not always been a concern; in fact, the first transplantation experiments in humans used animal organs more often than human organs... Before xenotransplantations were envisaged, the folklore already included stories of half man-half beast chimeras. Pre-historic cave paintings rarely represent people but, in the Lascaux cave in France (ca 15000 BC), the only representation of a human being shows a man with a head of a bird [plate included]. The gods of Ancient Egypt are often represented with the body of a man and the head of an animal: Anubis has the head of a jackal; the great Sphinx of Giza (ca 2500 вC) is a lion with the head of a woman. The first description of a xenotransplantation is recorded in Indian mythology, in a text in Sanskrit from the 12th century в . [Here the authors detail the origin myth of Ganesha, the elephant-headed son of Shiva and Parvati]... In Ancient Greece, Minotaur was a man with the head of a bull, Esfinge was a winged lion with the head of a woman, Centaurs were horses with the truck and head of a man. In Homer's Odyssey (ca $750 \mathrm{BC}$ ), the companions of Ulysses were transformed into half man-half swine chimeras by Cerce the sorceress. Closer to us, the legends of werewolves and vampires (man to bat) evoke hybrid beings, half man-half beast. ${ }^{4}$

For Deschamps et al., this xeno bestiary offers evidence of a widespread and natural human desire to meld disparate bodies, thus legitimating contemporary xeno science. Transpecies surgeries likewise have their own histories and, 
yet again, cursory accounts often follow historicized examples from ancient cultures. As Deschamps et al. (and others) assert, early surgical attempts at xenografting span several centuries; nevertheless, the early twentieth century marks the onset of a contemporary (understood simultaneously as modern) period, when various scientists (based in France, the U.S., and Russia especially) begin serious and rigorous experimentation with a range of species. For instance, in 1906, Alexis Carrel, a French-born 'experimental surgeon' (Friedman, 2007:6) based at Rockefeller University in New York, initiated efforts to transfer kidneys among sheep, pigs, goats, and primates, alongside other more daring attempts at transferring animal tissues to humans (Friedman, 2007, Lederer, 2008, Sade, 2007). These efforts are frequently described as converging by mid-century with watersheds in immunology and allotransplantation. In 1944, the British zoologist Peter Medawar determined that graft rejection was based on immunological responses, paving the way for the first successful kidney transplant between identical twins in Boston by a team that included surgeons who would similarly lead the charge in xeno research (Cooper, 2007). By mid-century, xeno had evolved into a semi-legitimate, albeit narrow research domain, and American scientists especially were firmly convinced that our primate 'cousins' - as evolutionarily related blood kin - were ideal 'donors.'

The discovery in the 1980s of the potent immunosuppressant cyclosporine proved to be a surgical boon in the U.S. and abroad. Alongside such progress, xeno exhibits a much rockier history, marked by ongoing failures at resolving immunological compatibility between humans and animals. Whereas primates were the animals of choice throughout much of transplant's early surgical era (from the mid-1950s to the early 1980s), in more recent decades primates have been marginalized, now deemed 'too close' (and, thus, I argue, incestuous) a match, only to be replaced by pigs who now dominate xeno experts' imaginings of these animals as promising an alternative and more successful marriage of embodied interspeciality.

PRIMATE PROXIMITY AND HUMAN VULNERABILITY

Much of the twentieth century is, without question, a simian epoch where the U.S. is concerned. Darwinian evolution inspired the use of primates in a range of emergent disciplines - including cognitive psychology, primatology, medical research, and military aeronautics. Although primate research began with observations in the wild, it soon shifted to the use of captured, captive animals, and, subsequently to the establishment of breeding colonies guaranteeing local access to particular primate species (Blum, 1994, Pardes et al., 1991, Fridman, 2002). This had a profound effect on naturalizing scientific views of primates 
as appropriate subjects for research relevant to clinical advancements in transplantation, too. Not so surprisingly, then, primates similarly dominated early attempts within xeno. Between 1906 and 1993, there were at least forty-three recorded attempts to transfer whole organs - most notably kidneys, hearts, and livers from macaques, baboons, and chimps to humans, the majority of these surgeries occurring in the U.S. (Deschamps et al., 2005, Taniguchi and Cooper, 1997). Interestingly, although we know which primates were used (and, in at least one instance, even the name of the specific animal), we know little about the patients who died serving as research subjects. Indeed, our understanding of the ethos that drives transplantation and xeno research would be enriched by a patient-centered history of experimental work. Instead, xeno's history most readily features the heroic efforts of prominent physicians and the knowledge and techniques their research produced.

I intend to make a case for an alternative experimental story, where species matching and the vulnerability of particular categories of human beings collide within the socio-moral framework of kinship. This 'collision' is evident on several fronts, especially within the United States. First, much of the pathbreaking work conducted mid-century occurred in the Deep South during a period marked by racial segregation and sanctioned violence under the legislation of Jim Crow, and during the early Civil Rights era of the 1950s and 1960s. Second, the rudimentary data on some key research subjects suggests that the indigent poor and, apparently, Southern black men, may well have been 'favored' as recipients of simian organs. There is much work to be done on the ethics of experimentation as framed by racist conventions. ${ }^{5}$ Within this essay, however, I am most interested in the relevance of race (and, to a lesser extent, that of other categories of vulnerability) in those very contexts where scientists imagine - or struggle with - questions of inter-species proximity. At these moments, human kinship with certain species is leveraged as a legitimizing social force that is then tested by U.S.-based xeno experts; this is most evident during a heightened period of experimentation that falls between the 1960 s and 1990 s. Because we currently lack comprehensive data on most patients' personal histories, the stories of specific surgeons' efforts will frame my own narrative. As I show, however, at certain moments key evidence emerges that tells us much about the parallel categories of human- and non-human primate vulnerability.

I begin with Keith Reemtsma (1925-2000), a pioneer in virtually every corner of transplant research. Although Reemtsma would later head important programs in Utah (1966-1971) and at Columbia University in New York (19711994), as physician Eric Rose has noted, 'Perhaps [Reemtsma's] most creative and certainly his most controversial work was in the field of cross-species 
transplantation' (Rose, 2000). As reported by Thomas Starzl, a leader in xeno and transplant research more generally, Reemtsma's early efforts instilled significant hope for several decades among xeno experts (Starzl, 1992).

During the mid-196os Reemtsma was based at Tulane University in New Orleans, Louisiana where he performed thirteen experimental kidney transfers from rhesus monkeys and chimps to humans. Most noteworthy are surgeries attempted in 1963 and 1964, involving the transfer of kidneys from a Rhesus monkey into a thirty-two-year-old woman; when the kidneys failed they were removed, and the woman died. Yet another patient was a twenty-three-year-old female school teacher, who received a chimpanzee's kidney and who survived nine months, ultimately dying from an overwhelming infection ${ }^{6}$ (Barbour, 1964, Rose, 2000, Deschamps et al., 2005). The third and perhaps most celebrated attempt occurred on November 5, 1963, when Reemtsma's twelve man team from Tulane transferred a chimpanzee's kidneys to 'a 44-year old New Orleans doc worker' named Jefferson Davis at the New Orleans Charity Hospital (Eagle, 1963). As reported at the time, 'the university said Davis is believed to be only the second person [sic.] ever to receive kidneys from a primate - and the first to recover sufficiently to leave the hospital' (Eagle, 1963). As reported months later:

... Davis, who gave his consent, walked out of a New Orleans hospital six weeks after his operation. Two days later, he [returned with] what was to be fatal pneumonia, his resistance weakened by the same drugs that enabled him to keep his life-saving kidney transplants. He died Jan. 6. But for two months and one day, the kidneys of a 90-pound chimpanzee had kept Davis alive after his own kidneys had failed (Barbour, 1964).

Sadly, we lack important details on the other patients. Nevertheless, several aspects of Davis's story are worth noting: first, Davis is identified as an AfricanAmerican dock worker; second, that his surgery occurred in the Deep South; third, that it occurred at a time when segregation was rampant in this region of the U.S.; and, finally, whereas the surgical team hailed from Tulane, an elite (and, until 1963, an all white institution), ${ }^{7}$ the surgery itself was conducted at Charity Hospital, one of numerous institutions bearing similar names scattered throughout the South specifically to administer medical care to AfricanAmericans and, at times, indigent whites. ${ }^{8}$ Reemstma made still other attempts when based at Tulane, although subsequent patients similarly succumbed to infections, dying within 8-63 days (Altman, 2000). 
Whereas the significance of race is generally downplayed - or even erased within contemporary accounts of xeno's history, it is, nevertheless, a significant factor in shaping its experimental trajectory. During this period there was in fact a flurry of activity based most notably - though, as we shall see, not exclusively - in the South. David Hume, an established leader in allotransplantation was present during the first successful human kidney transfer between identical twins in Boston in the 1950s; he subsequently moved to Richmond, Virginia, where in 1964 he, too, transplanted a chimpanzee's kidney into a man. ${ }^{9}$ Nowhere is the significance of race more evident, however, than in the efforts of the celebrated surgeon Christiaan Barnard, who trained in the U.S. and then returned to South Africa where he made international headlines in 1967 for attempting the world's first human heart transplant. Although rarely reported, Barnard's efforts were informed by his earlier attempts at xeno transplantation that same year, when he transferred a baboon heart to a twenty-five-year-old woman, and a chimpanzee's heart to a sixty-year-old man (Fox and Swazey, 1992: 213, note 60). Also, when Barnard performed the world's first heart transplant, he deliberately transferred this vital organ across the Colour Bar, as detailed below.

Interestingly, whereas Barnard's story dominates most transplant histories, xeno experts generally grant credit to James Hardy. Hardy was already well known - alongside Joseph Murray and David Hume - for having successfully transferred a kidney between identical twins in Boston in 1954. Hardy subsequently moved to the University of Mississippi. As is often reported in xeno circles, months before Barnard in 1967, Hardy implanted the heart of a chimp named Bino into a sixty-eight year-old comatose man in Jackson, Mississippi. Although Hardy had originally planned to use a human heart, the donor died earlier and more quickly than anticipated. In response, members of Hardy's surgical team (save one, who abstained) voted to attempt the xeno graft instead (Barbour, 1964). Unlike Bino, the human patient's identity remains unknown; nevertheless, racial politics figured prominently here. According to an obituary on the University of Mississippi Medical Center's web page, Hardy

...brought renown to UMC and the state of Mississippi for advances in medical science that literally caused the world to pause and take notice at a time in Mississippi's history when the state was receiving almost daily national publicity that chronicled the lawless violence and racial intolerance of the civil rights era... Dr. Hardy reminded the world that Mississippi was a repository of great intellectual curiosity, scientific competence and universal compassion for the human condition. ${ }^{10}$ 
This discourse is reminiscent of Barnard's story. When a 'Coloured' woman named Denise Darvall, died from injuries sustained in a car accident, Barnard transplanted her heart in Louis Washkansky, who was legally categorized as 'White.' Barnard also transferred Darvall's kidneys to a 10-year-old 'Coloured' child named Jonathan van Wyk (of whom we know surprisingly little) (LIFE, 1967). Within dominant public narratives, Barnard is portrayed as an enlightened figure who leveraged human organ transfer in defiance of the Colour Bar of Apartheid South Africa, where, not unlike the Jim Crow American South, racist legislation and sanctioned brutality codified white paranoia about interracial, embodied forms of intimacy.

Like Barnard, then, Hardy proved cognizant of the deep, social ambiguities associated with his respective attempts at xeno surgeries. At the time, in fact, Hardy described his effort as having 'precipitated intense ethical, moral, social, religious, financial, governmental and even legal concerns', because 'We had not transplanted merely a human heart, we had transplanted a subhuman heart' (TransplantWeek, 2003, italics added) and into what many contemporary white southerners would have considered a subhuman and even simian-like patient. As such, Hardy's experiment raises important questions about embodied intimacy and interspecies kinship.

I believe that Reemtsma's and Hardy's actions (alongside those of still other unnamed members of their surgical teams) were driven by complicated motives, involving the simultaneous, disturbing mixture of enlightened medical thinking with racialized experimentation, which together bore special meaning in the American South and elsewhere during the mid-1960s. Importantly, every xeno surgery inevitably tests to see if the human body can cope with the implantation of a fleshy part from a disparate species. Sadly, if read through a racist lens, Reemtsma's and Hardy's attempts were both immunological experiments and social projects that tested the proximity of 'sub-human' primates and racialized 'sub-human' Blacks as transitional research subjects. That is, vulnerable Blacks apparently served at key moments as human species proxies during the provisional and transitional testing of inter-species kinship. If a chimp's heart or kidneys could function in a black body, perhaps these organs might function in the bodies of any human being.

These experiments thus emerge as a perverse sort of embodied intimacy: if the match makes good, the primate is elevated to a confirmed ideal surgical marriage with humans, and the black man's humanity is redeemed when he serves as experimental surrogate. Ultimately, though, the social weight of racialized kinship in the U.S. was too heavy a burden for xeno science to bear. 
After Reemtsma's and Hardy's efforts failed, research shifted away from the inclusion of Southern Blacks - and, furthermore, out of the South - only to incorporate still other vulnerable groups, including members of the underclass and children, during subsequent, sporadic attempts to test the limits of simian/ human compatibility. ${ }^{11}$

VULNERABLE PROXIES

Ultimately, two high profile failures would bring primate-to-human organ transfer to an end. The first involved the controversial case of Baby Fae, a twelve-day-old white infant born with a severe cardiac abnormality who in 1984 received a baboon heart transplant at Loma Linda, a Seventh Day Adventist Hospital in Southern California (Fitzpatrick, 2009). Baby Fae was vulnerable in a host of ways that compounded her delicate medical state. Her mother was unmarried, poor, and only twenty-three, she already had another toddler, the father had abandoned the family shortly before Baby Fae's birth, and both parents had had brushes with the law. Her mother was told nothing could be done to save her baby, and so she took her home to die. She then received a call offering a baboon heart transplant, and she consented although she later reported that at the time she thought it was 'mad science' (Knoll and Lundberg, 1985:3360; Bailey et al., 1985; A BC, 1996; PBS, 2002). Baby Fae's innocent vulnerability briefly squelched the monstrous qualities of xenografting; when she survived less than a month she dealt a serious blow to xeno research.

Bailey - an obscure cardiac surgeon at a little known medical institution - was challenged far and wide by ethicists, and ostracized and marginalized by established xeno experts (Annas, 1985, Capron et al., 1985, Jonasson and Hardy, 1985, Knoll and Lundberg, 1985, Kushner and Belliotti, 1985, Reemtsma, 1987, Stoller, 1990, McCormick, 1987, Nature, 1984). In the wake of this failed surgery a decade-long, global moratorium of human research ensued (Deschamps et al., 2005). Yet another controversy arose when Bailey later disclosed on Australian radio that, as a Seventh Day Adventist, he did not believe in Darwinian evolution; in response, pediatric cardiologist Welton Gersony declared during the same program that Bailey's actions had 'created a circus in fact' (ABC, 1996). More importantly, Bailey's dismissal of evolution outraged xeno experts whose very work was driven by the idea that primates, as our evolutionary cousins, were ideal human matches. Bailey threatened to jeopardize the Darwininan model of human-primate proximity, and to this day American xeno experts regularly pass over Baby Fae when they recount their discipline's history.

Final attempts at primate-to-human transfers were conducted in the U.S. in 
1992 and 1993 by Thomas Starzl in Pittsburgh, Pennsylvania who posited that the immunosuppressant FK506 might suppress the human response to transplanted baboon livers. Starzl relied on a new category of vulnerable patients, terminally ill adult males ineligible for allografts because of HIV and/or hepatitis $\mathrm{C}$ infections. After his first two patients died (one survived 70 days but spent 26 in a coma), he terminated the research (although he had permission for a third), faced with insurmountable immunological hurdles and increased public concern. Starzl's efforts were targeted by animal activists, who dubbed him 'Dr. Starzlstein,'12 for what they perceived to be monstrous efforts to meld animal and human bodies.

Activists concerned for the welfare of laboratory animals (and during this period, for primates in particular) (Blum, 1994) honed in on xeno as monstrous and barbaric medical experimentation. In Europe Baby Fae had already generated especially 'intense feelings and massive protest action[s]'; when scientists in the U.K. proposed the first transgenic organ transplant in 1996, a comprehensive study by Nuffield Council on Bioethics ruled against the use of human subjects (Lundin, 1999:19; Nuffield, 1996), a ban that remains in place today. As a result, xeno experts frequently describe their field as 'dead' in that country. Pragmatic difficulties associated with acquiring and working with monkeys and apes also intensified, with financial constraints and protective legislation for laboratory animals regularly derailing efforts in several countries. At this point it was clear that compatibility with our primate cousins had failed. Xeno experts searched in earnest for another species, and they landed squarely on the pig.

\section{PORCINE PROMISES}

When American science students take anatomy, they inevitably dissect fetal pigs who serve as human proxies. The pig's potential within xeno science was posited mid-century by the celebrated British transplant surgeon Sir Roy Calne, who 'realized' pig-to-baboon liver transfers as a 'logical approach before attempting clinical trials on man' (Deschamps et al., 2005:97). Efforts at porcine-to-human organ transfer were nevertheless sporadic for the next three decades. Today, however, porcine research defines an emergent chapter in xeno's progression, and in conclusion I touch on it briefly for the contrasts it offers to experts' imaginings of human/primate compatibility. Among the earliest attempts at porcine organ transfer occurred in 1966 when René Kuss, a French urologist, transferred two kidneys from a pig into a patient suffering from end-stage renal failure. Graft rejection was immediate, and Kuss removed the organs after 48 hours, at which point the patient died. As Kuss himself 
reported years later, the incompatibility of these stranger species was insurmountable and, even, psychologically debilitating; as he is quoted as saying, 'Somewhat less fortunate than Reemtsma's and Starzl's trials of animal grafts ... using anthropoid donors, I retained from this painful experience a xenophobia for xenografts which remains with me today!' (Cooper, 2007:93).

Subsequent attempts with pigs were revived only in the 1990 and in the wake of the moratorium on primate-to-human grafts. Three attempts (for which few data exist) occurred between 1992 and 1996: one in Los Angeles involving the transfer of a pig liver to a woman as a temporary 'bridge' to allotransplantation; and two other transfers of pig hearts to human patients in Poland and India. These three patients died within 34 hours, 23 hours, and 7 days, respectively. ${ }^{13}$ Also, some porcine tissues have been implanted experimentally in humans, viewed by many as a means to test autoimmune responses on a manageable scale. In 1995, for instance, Jeff Getty, who was infected with AIDs, received baboon bone marrow cells at San Francisco General Hospital, a surgery performed by Dr. Suzanne Ilstaad. Because baboon stem cells are resistant to AIDS, Ilstaad hoped they might boost Getty's immune system; the transplant failed (but appeared to cause no harm, remaining in his system for only two weeks) (Frontline, March 2001).

Today Calne's words are read as prophetic in various quarters: when taken together, these recent efforts mark an emergent interest in using pigs as an alternative to primates. Within the last twenty years xeno experts based most notably in the U.S., New Zealand, and Australia have come to embrace the promises of porcine xeno grafting, a move prompted by the realization that primates had proved immunologically and socially untenable. As a result, our primate 'cousins' - most notably macaques and baboons - have subsequently shifted to an intermediate, experimental recipient position, now standing in as surrogates for humans (much as did black men and other vulnerable subjects before) to test the possibilities of cross-species grafts in anticipation of porcine to human transfers.

Today, xeno experts speak of pigs as a newly imagined, ideal match for our species in terms that elide their anatomical proximity with their pragmatic value. Pigs are described frequently during interviews as 'purely commercial animals' that can be 'fattened and driven to market' within two years of birth; they can be bred with ease in captivity, their litters are large and thus they reproduce rapidly, and, in the U.S. at least, they are categorized as farm rather than laboratory animals, and so they are exempt from the stricter regulatory apparati that restrict primate research. In the age of genomics, xeno experts alter the genetic 
makeup of swine herds so that they may be immunologically more compatible with humans. They also dream of chimeric swine whose bodies might incorporate genetic material from specific patients so that a particular piglet might be bred and raised for them. In kinship terms, pigs are emerging as a specialized category of affine, raised in anticipation of a future embodied marriage.

Porcine xeno has thus faced its own set of challenges, where zoonoses that might jump the species barrier prove especially troublesome. In 1998 Fritz Bach, a well-known immunologist and xeno expert based at Harvard, publicly declared a moratorium essentially on his own research, alarmed by the potential dangers porcine endogenous retroviruses (or PERVs) might pose to humans. His action led to hearings at the FDA in the U.S. (Bach et al., 1998, Frontline, March 2001), and by 1999 the FDA had banned the use of primates as organ 'donors.' New regulatory apparati slowed porcine research substantially, too, echoing similar developments in England and France (Deschamps et al., 2005:103-4). Involved scientists realized they needed to focus their efforts on further domesticating the pig by producing pathogen-free herds of swine destined specifically for xeno research.

As xeno experts intensify their efforts in genetic engineering, the farm pig is beginning to resemble a laboratory rat. In the contemporary age of PERV, however, no one has yet attempted to transfer a whole organ from a pig to a living human patient. Instead, xeno experts remain in a holding pattern of sorts, focusing their efforts on how best to produce new strains of safe, transgenic swine. An immediate response has involved pathogen-free animals in isolation; xeno experts have likewise focused attention on producing genetically altered animals. Among the most celebrated are Gal 'knock-out' pigs produced through in-vitro genetic manipulation during initial reproductive stages. These animals - and their offspring - lack an enzyme that plays a partial role in stimulating hyperacute rejection of xenografts (Zhong, 2007, Kieman et al., 2008). Still others advocate reviving an old yet abandoned (and controversial) technique that would involve radiating a recipient prior to xenografting. These and related efforts are designed to deceive the human immune system into accepting pig tissue as 'self' rather than 'foreign.'

Xeno experts nevertheless speak of pigs as a new and superior match that stands against now archaic understandings of primates. I am often told that pigs are so similar anatomically to humans as to be indistinguishable' from us, and they can be bred for size so that their organs are a near perfect 'fit. ${ }^{\text {'4 }}$ Some even elide anatomy with evolutionary proximity, which in fact is scientifically unfounded: as omnivores their evolution parallels ours because they have 
adapted to similar environments, but they are by no means close evolutionary cousins. This imagined, evolutionary sameness is rooted in our ability to manipulate pigs genetically and, thus, transform 'difference' into 'sameness' or a 'foreign species' into 'self'. Because generations of pigs can be bred in fairly rapid succession and genetically altered, too, pigs emerge as 'evolutionarily close' to us because we can make them so. For now, the match is only approximate, and so pigs stand as idealized and desired future affines whose tissues we might one day 'marry' with our own.

\section{CONCLUSION: RETHINKING KITH AND KIND}

The grammar of kinship thus aids us in disentangling this emergent preference for simians and swine: whereas primates, as true evolutionary 'cousins' are spoken of as blood kin, pigs represent an altogether different sort of match, as exemplified by a statement made by a leading Australian xeno expert who declared that because primates were genetically too close to humans ${ }^{15}$ they harbored significant dangers: that is, because of their evolutionary proximity, simians could easily transmit species-specific, life threatening pathogens in ways that pigs, presumably, would not. For now, at least, this statement reconfigures the union between humans and primates as an unproductive and incestuous one, whereas pigs, which are evolutionarily more distant, can be manipulated genetically so as to emerge as an altogether different and newly imagined perfect partner.

In this vein, sociologist Peta Cook has argued that 'different techniques can be used to justify particular realities.' As she explains, when xeno experts shifted their attention from simians to swine, 'compatibility' foregrounded the 'practicality' of an evolutionary 'discordant' species in place of earlier 'concordant' arguments that justified the use of non-human primates (Cook, 2006:2-3). As I have sought to show, xeno experts draw more specifically on the morality of kinship as they reframe inter-species compatibility. Lurking in the shadows, though, are the monstrous qualities of perverse, embodied unions; when reconfigured as blood and, then, affinal kin, simian and porcine species reemerge as 'natural' companions or suitable, malleable, matches. Through xeno's efforts, strangeness and difference are transformed into sameness and self.

Once interminable failure plagued primate experiments, simian species emerged as 'too close' in their evolutionary proximity to humans to be a suitable match. As a result, they experienced a double shift. First, their uneasy proximity was reread as an incestuous (and, thus, potentially, monstrous) union, where incest indeed marks the inversion of sameness and strangeness. 
Second, various primate species were orphaned to a transitional position formerly occupied by a few black men in the American South and subsequently by other vulnerable patients. No longer valued as the fair cousins of organ transfer, primates now serve as experimental proxies to test donor-recipient compatibility across the species divide.

Pigs now stand as the new darling in an emergent category of xeno research, set against a complex socio-moral terrain. Facilitated by the genomic revolution, xeno experts now bank on their skills to reorder the porcine immune system and thus render this animal compatible with humans. By transforming this distant species into 'same' and 'self', pigs provoke newly imagined possibilities for interspecies intimacy. When read through the lens of kinship, primates and pigs emerge as newly-imagined blood and affinal kin, thus laying bare scientists' simultaneously strange and sentimental longing for newly imagined forms of interspeciality. Such is the dream of xeno science, an anticipatory realm of interspecies relatedness, sameness, kinship, and kind.

\section{ACKNOWLEDGMENTS}

This essay originated as a talk delivered at the day-long Conference on "The Future of Organ and Tissue Donation," School of Social and Cultural Studies, Victoria University of Wellington, an exceptional event organized by Rhonda Shaw. I thank her for her insightful knowledge on organ transfer in New Zealand, alongside her warm hospitality. Also, comments and suggestions from conference participants, P. Cook, D. Tucker, J. Marks, L. Bishop, M. Banner, and several anonymous interviewees have enriched my understanding of transplantation in New Zealand, and the significance of animals in science. This project is funded by several Barnard College faculty grants and by the National Science Foundation (Award \#0750897). Any opinions, findings, and conclusions or recommendations expressed in this material are those of the author and do not necessarily reflect the views of either institution.

\section{NOTES}

1 I employ the expression 'human organ transfer' to underscore the inseparability of procurement, donation, and transplantation; see (Sharp, 2006).

2 Within these countries, xeno research is currently most active in the U.S., Australia, and New Zealand. Specialists with earlier experience are currently resident in Canada and the U.K., even though active work may be prohibited (as is the case in the U.K.). These five countries do not hold exclusive claims on xeno, 
however: other centers of activity include (but are not limited to) Japan, China, Singapore, Germany, Italy, and Mexico.

3 http://www.asts.org/Chimera/, accessed 2/21/10.

4 An creative rendering of these stories, certainly: it proves difficult to imagine Ganesha's acquisition of an elephant's head as a transpecies surgery; Homer's tale of Cerce's island involved the unwilling transformation of Odysseus' (or, when Romanized, Ulysses') crew into sentient swine (not half men-half pigs); and archaeologists hardly agree on whether the 'birdman' of Lascaux is, indeed, part fowl, although a bird image appears nearby. The veracity of Deschamps et al's description is not the issue, however: I am most concerned with how such narratives serve to legitimate contemporary xeno science.

5 Among the most infamous cases involved the withholding of treatment from African-American men infected with syphilis at Tuskegee, Alabama; the research spanned forty years.

6 Xeno experts continue to puzzle over the reason for her impressively long period of survival.

7 In 1963 Tulane, an all-male school, admitted eleven African-American students; its sister school, Newcomb College, admitted one. See: http://tulane.edu/nccrow/ newcomb-archives/history-of-newcomb-college.cfm.

8 This story - and its outcome - are laced with still other tragic ironies: the patient himself bore the name of the President of the Confederacy; equally poignant, an overview of the surgery's outcome published in a Florida newspaper in 1964 appeared next to yet another whose headline proclaimed 'Racial Economic Gap is Widening' (Tribune, 1964).

9 Interestingly, Virginia Commonwealth University Medical Center proclaims that 'In 1963, the first "xenotransplant" in Virginia with successful function of the chimpanzee kidney into a human was performed at MCv' (www.vcuhealth. $\operatorname{org} /$ ? $i d=464 \& \operatorname{sid}=1$, consulted 7.19.10) the patient did, in fact, die within a day (Taniguchi and Cooper, 1997).

10 http://www.umc.edu/about_us/hardy_obituary.html; consulted 2/25/10. Within the American context, this is a rather remarkable reworking of this state's history: at the time, Mississippi was considered a bastion of sanctioned segregationist policies within educational, medical, legislative, and judicial realms. 
11 Other sporadic attempts at xeno in the U.S., France, Italy, and South Africa similarly failed, with patients generally dying within days - or, sometimes, weeks - from pneumonia, cardiogenic shock, vascular hyperacute rejection, and sepsis. For comprehensive historical overviews of other xeno surgeries, with special emphasis on the 1960s onward, see: (Deschamps et al., 2005, -, 2003, Auchincloss Jr., 1988, Reemtsma, 1987, Starzl, 1992, Taniguchi and Cooper, 1997, TransplantWeek, 2003).

12 I became aware of this nickname during interviews with activists, who used it freely and frequently.

13 Details of the Los Angeles case were not published until 1995, three years after the surgery; the Indian physician was arrested for violating his country's Human Organ Transplantation Act of 1994 (Deschamps et al., 2005).

14 As noted recently by Cook, baboon and chimp hearts are either too small or unable to cope with human circulatory needs (Cook, 2006: 6, citing findings by Hardy and others).

15 'Four Corners', Australian National Radio, 25 August 1997. Consulted 6/o9.

\section{REFERENCES}

(ABC), A.B.C. 1996 Artificial Hearts. The Health Report with Norman Swan, Radio National Transcripts. Monday, January 15 ed. Australia, ABC Radio National.

Altman, L.K. 2000 Keith Reemtsma, 74, Pioneer in Medical Transplants, Dies (Obituary), Tuesday, February 10. The New York Times.

Annas, G.J. 1985 'Baby Fae: The "Anything Goes” School of Human Experimentation', Hastings Center Report, 15:15-17.

Auchincloss Jr., H. 1988 'Xenogeneic Transplantation. A Review', Transplantation, 46:1-20.

Bach, F.H., Fishman, J.A., Daniels, N., Proimos, J., Anderson, B., Carpenter, C.B., Forrow, L., Robson, S.C. \& Fineberg, H.V. 1998 'Uncertainty in Xenotransplantation: Individual Benefits Versus Collective Risk', Nature Medicine, 4:141-144.

Bailey, L.L., Nehlsen-Cannarella, S.L., Conception, W. \& Jolley, W.B. 1985 'Baboonto-human Cardiac Xenotransplantation in a Neonate,' JAMA, 1985:3321-3329. 
Barbour, J. 1964 Risky Frontier: Medics Experiment with 'Spare Parts' Sarasota Herald Tribune (via AP news). Sarasota FL.

Bateson, G. 1958 Naven. A Survey of the Problems Suggested by a Composite Picture of the Culture of a New Guinea Tribe Drawn from Three Points of View, Stanford, Stanford University Press.

Blum, D. 1994 The Monkey Wars, New York, Oxford University Press.

Brodwin, P.E. 2000 Introduction. In Brodwin, P.E. (Ed.) Biotechnology and Culture: Bodies, Anxieties, Ethics. Bloomington, Indiana University Press.

Capron, A., Regan, T., Reemtsma, Sheldon, K.R., Mccormick, R., Gore, J., A., Trachtman, L. \& Annas, G. 1985 'The Subject is Baby Fae (Commentaries),' The Hastings Center Report, 15:8-17.

Cook, P.S. 2006 Science Stories: Selecting the Source Animal for Xenotransplantation. Social Change in the 21st Century, Centre for Social Change Research, Queensland [Australia] University of Technology.

Cooper, D.K.C. 2007 'René Kuss's Clinical Experience with Pig Kidney Transplantation in 1966 (Letter to the Editors)', Xenotransplantation, 14:93.

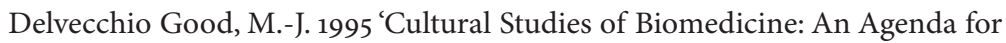
Research', Social Science and Medicine, 41:461-473.

Delvecchio Good, M.-J. 2001 'The Biotechnical Embrace', Culture, Medicine and Psychiatry, 25:395-410.

Deschamps, J.-Y., Roux, F.A., Sai, P. \& Gouin, E. 2005 'History of Xenotransplantation,' Xenotransplantation, 12:91-109.

Eagle, R. 1963 Man Who Received Transplant of Kidney from Chimpanzee Seen in 'Good Health'. Reading Eagle.

Fisher, M. 2002 'Familiar and Foreign Bodies: A Phenomenological Exploration of the Human-Technology Interface, JRAI, 8:333-346.

Fitzpatrick, L. 2009 A Brief History of Heart Transplants. Time.com, Monday, November 16; consulted 3.1.10. 
Fox, R.C. \& Swazey, J.P. 1992 Spare Parts: Organ Replacement in American Society, Oxford, Oxford University Press.

Franklin, S. 2007 Dolly Mixtures: The Remaking of Genealogy, Durham, Duke University Press.

Fridman, E.P. 2002 Medical Primatology: History, Biological Foundations and Applications (Ronald D. Nadler, editor; translated from the Russian by Roman Selivanov and Evgeniy Morozov), London, Taylor \& Francis Inc.

Friedman, D.M. 2007 The Immoralists. Charles Lindbergh, Dr. ALexis Carrel, and their Daring Quest to Live Forever, New York, Harper Perennial.

Frontline, P. 2001 (March) Organ Farm. Frontline.

Frontline, P. 2001 (March) Organ Farm: The Business of Xenotransplantation, Past and Present. PBs.

Garkavenko, O., Emerich, D.F., Muzina, M., Muzina, Z., Vasconcellos, A.V., Fergu-

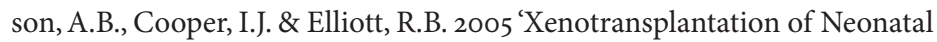
Porcine Liver Cells,' Transplantation Proceedings, 37:477-80.

Geertz, C. 1973 The Interpretation of Cultures, New York, Basic Books, Inc.

Ginsburg, F.D. \& Rapp, R. (Eds.) 1995 Conceiving the New World Order: The Global Politics of Reproduction, Berkeley, University of California Press.

Haraway, D.J. 1989 Primate Visions: Gender, Race, and Nature in the World of Modern Science, New York, Routledge.

Jonasson, O. \& Hardy, M.A. (1985) ‘The Case of Baby Fae’, JAMA, 254:3358-3359.

Kieman, K., Harnden, I., Gunthart, M., Gregory, C., Meisner, J. \& Keams-Jonker, M. 2008 'The Anti-Non-Gal Xenoantibody Response to Xenoantigens on Gal Knockout Pig Cells Is Encoded by a Restricted Number of Germline Progenitors', American Journal of Transplantation, 8:1829-1839.

Knoll, E. \& Lundberg, G.D. 1985 'Informed Consent and Baby Fae', JAMA, 254:33593360 . 
Kushner, T. \& Belliotti, R. 1985 'Baby Fae: A Beastly Business', Journal of Medical Ethics, 11:178-183.

Lederer, S.E. 2008 Flesh and Blood: Organ Transplantation and Blood Transfusion in Twentieth-Century America, New York, Oxford University Press.

LIFE 1967 The Gift of a Heart. LIFE.

Lundin, S. 1999 'The Boundless Body: Cultural Perspectives on Xenotransplantation', Ethnos, 64:5-31.

Malinowski, B. 1961 (1922) Introduction: The Subject, Method and Scope of This Inquiry. Argonauts of the Western Pacific. Prospect Heights, Waveland.

Mandell, A. 2010 Transplanted Pig Cells May Bring Relief from Insulin Injections in Type I Diabetics. The Medical News (from News-Medical.Net).

McCormick, R.A. 1987 Was There Any Real Hope for Baby Fae? In Cowan, D.H., Kantorowitz, J.A., Moskowitz, J. \& Rheinstein, P.H. (Eds.) Human Organ Transplantation: Societal, Medical-Legal, Regulatory, and Reimbursement Issues. Ann Arbor, Health Administration Press in Cooperation with the American Society of Law and Medicine.

NATURE 1984 Grandstand Medicine: Baboons' Hearts are not Taboo for People, but Medicine Which is not Essential is Wrong. Nature, 312, 88.

NUffield 1996 Animal-to-Human Transplants: The Ethics of Xenotransplantation. Nuffield Council on Bioethics. London, Nuffield Council on Bioethics.

Pardes, H., West, A. \& Pincus, H.A. 1991 'Physicians and the Animal-Rights Movement,' New England Journal of Medicine, June 6:1640-1643.

PBS 2002 Sparing No Expense. Online News Hour. Public Broadcasting Corporation.

Percy, W. 1958 'Symbol, Consciousness and Intersubjectivity', Journal of Philosophy, 55: 631-642.

Rabinow, P. 1992 Artificiality and Enlightenment: From Sociobiology to Biosociality. In Crary, J. \& Kwinter, S. (Eds.) Incorporations: Zone 6. New York, Urzone, Inc. 
Ragoné, H. 1996 'Chasing the Blood Tie: Surrogate Mothers, Adoptive Mothers and Fathers', American Ethnologist, 23:352-365.

Rapp, R. 2000 Testing Women, Testing the Fetus: The Social Impact of Amniocentesis in America, New York, Routledge.

Reemtsma, K. 1987 Clinical Urgency and Media Scrutiny. In Cowan, D.H., Kantorowitz, J.A., Moskowitz, J. \& Rheinstein, P.H. (Eds.) Human Organ Transplantation: Societal, Medical-Legal, Regulatory, and Reimbursement Issues. Ann Arbor, Health Administration Press in Cooperation with the American Society of Law and Medicine.

Rivers, W.H.R. 1971 The Geneaological Method [original publication 1910]. In Graburn, N. (Ed.) Readings in Kinship and Social Structure. New York, Harper and Row.

Rose, E.A. 2000 'In Memoriam: Keith Reemtsma (1925-2000)', Journal of Thoracic and Cardiovascular Surgery, 120: 627-628.

Sade, R.M. 2007 'Reflections on Emerging Technologies at the Centennial of Organ Transplantation (Introduction)', Journal of Law, Medicine, and Ethics, Summer, 235-236.

Schneider, D.M. 1980 (1965) American Kinship A Cultural Account, Chicago, University of Chicago Press.

Sharp, L.A. 2001 'Commodified Kin: Death, Mourning, and Competing Claims on the Bodies of Organ Donors in the United States', American Anthropologist, 103:1-21.

Sharp, L.A. 2006 Strange Harvest: Organ Transplants, Denatured Bodies, and the Transformed Self, Berkeley \& Los Angeles, University of California Press.

Sharp, L.A. 2011 'Monkey Business,' Social Text, special collection on "Species," J. Livingston and J. Puar, eds. 29:43-69.

Starzl, T.E. 1992 The Puzzle People: Memoirs of a Transplant Surgeon, Pittsburgh and London, University of Pittsburgh Press.

Stoller, K.P. 1990 Baby Fae: The Unlearned Lesson. Perspectives on Medical Research (online journal @ www.curedisease.com); published by Ameri- 
cans/Europeans/Japanese for Medical Advancement, 2.

Strathern, M. 1992 Reproducing the Future: Anthropology, Kinship, and the New Reproductive Technologies, New York, Routledge.

Taniguchi, S. \& Cooper, D.K.C. 1997 'Clinical Xenotransplantation: Past, Present and Future,' Ann R Coll Surg Engl, 79:13-19.

Taussig, K.-S. 2004 'Bovine Abominations: Genetic Culture and Politics in the Netherlands', Cultural Anthropology, 19:305-336.

TransplantWeek 2003 Online News: James Hardy (Obituary). Transplant Week, 4.

Tribune, S.H. 1964 Racial Economic Gap is Widening, Sarasota Herald Tribune.

Zhong, R. 2007 'Gal Knockout and Beyond', American Journal of Transplantation, 7:5-11. 